\title{
A Digital Recording Consciousness: Analysing, Mixing and Evaluating Audio in the Mashup Community
}

\author{
Maarten Michielse \\ Maastricht University \\ m.michielse@maastrichtuniversity.nl
}

\begin{abstract}
This article investigates a specific musical sensibility that plays a role within the mashup community and makes it possible for participants to re-use and recombine recorded songs in new and imaginative ways. Inspired by the work of H. Stith Bennett, I call this sensibility a "digital recording consciousness". In order to be able to participate in the community, mashup enthusiasts need to develop an in-depth understanding of digital audio files and interrelated software programs. By tinkering with existing tracks and by commenting on each other's work, mashup enthusiasts strive to collectively explore and develop such technical knowhow further. Based on a (virtual) ethnographic investigation of mashup community Mashstix.com, this article investigates these communal processes in detail. Instead of highlighting topics such as piracy and theft, it develops a focus on community interactions, competences and skills. These aspects play a key role in the values and meanings assigned by mashup enthusiasts to their practice.
\end{abstract}

KEYWORDS: mashup practices, recording consciousness, digital technology, skills, learning 


\section{Introduction}

Within the field of popular music, mashup practices are often understood as inherently subversive activities in which the ironic and illegal recombination of songs, artists and genres is key. ${ }^{1}$ As such, the focus in the academic literature lies mainly on topics such as privacy (Demers 2006; McLeod and DiCola 2011), activism (Howard-Spink 2005; McLeod 2005), and humour (Brøvig-Hanssen and Harkins 2012). Only rarely more technical and skills-oriented aspects of mashup culture are considered, such as its specific relation to (digital) recording technologies and interrelated musical and technical skills. This is unfortunate as mashup enthusiasts often associate the significance of their practice specifically with such technologies and skills. The production of a mashup typically involves layering a vocal track of a song (a so-called "a cappella") with a backing track (instrumental) of another song, usually from a different artist, genre or era. The goal is to blend these two tracks as seamlessly as possible, making them sound as if they were recorded at the same time, in the same studio. ${ }^{2}$ To perform this task well, one needs to have a good understanding of recordings and their different characteristics and affordances. Moreover, it demands extensive knowledge of digital software programs such as Ableton Live or Cubase, which are used to analyse, recombine and rework these source materials. For mashup enthusiasts, such qualifications are not just an important condition for participation-they are crucial to building esteem within the community.

In online communities such as Mashstix.com (www.mashstix.com), thousands of mashup enthusiasts come together to share their practices. These online platforms function as important "communities of practice" (Lave and Wenger 1991; Wenger 1998) in which members are able to collectively test, discuss and improve their knowledge and skills. Participants evaluate aesthetic aspects as well as technical processes, such as the quality of source materials or issues of mixing and mastering. By sharing their self-made mashups with the community, participants showcase their ability to work with a wide set of sources and digital audio technologies. At the same time, participants, by commenting on submitted mashups, also prove that they are able to evaluate and critique the use of such sources and technologies by others.

As my argument will underscore, issues of subversion or illegality are hardly central to the everyday activities of such mashup communities, at least not when regarded from the perspective of the participants. ${ }^{3}$ Instead, these communities emphasize the collective exploration and showcasing of, what I call, a "digital recording consciousness". This term builds on H. Stith Bennett's (1980) original theory. In his work, Bennett describes a "recording consciousness" as a particular form of aural awareness which emerged with the rise and spread of physical audio recordings and interrelated studio technologies such as multitrack systems, filters and equalizers (see also: Babich 2014; Middleton 1990; Milner 2009). Being able to understand such technologies is crucial especially for rock musicians and sound engineers; often, their professional identities are even founded on it (Bennett 1980; Kealy 1990). As I will argue, for mashup enthusiasts it is an important aspect of their identity as well. For them, however, this recording consciousness is embedded in a very particular set of practices in which 
not the production of new recordings is key, but the digital manipulation of large amounts of existing audio files and formats. Moreover, rather than being centred on traditional studio settings and physical audio media, their musical understandings and skills are intertwined with a wide variety of digital home audio workstations, software programs and online platforms. As such, the type of recording consciousness that is centre-stage in these communities is particularly different from what Bennett had in mind when he first coined the term.

Taking Bennett's theory as a starting point and building on a virtual ethnographic study of mashup community Mashstix.com, this article investigates the different roles of a digital recording consciousness within mashup practices. How do mashup enthusiasts talk and think about recorded sound in a digital era? What kind of musical and technical skills are of interest to them? And how do they define themselves through a particular conceptualisation and use of digital audio technologies? Addressing these questions is important because it can provide us with new information about the value and meaning of these practices among large groups of online music enthusiasts. In the last decade, the mashup community has changed from an underground-based movement into a popular mainstream phenomenon (Tapscott and Williams 2006). In this context, mashup practices have become less about rebellious musical attitudes and more about the collective sharing and discussing of all sorts of skills and techniques. While some authors explored such collective practices in part (McGranahan 2010; Roseman 2007; Shiga 2007), none of them has explicitly put the notion of "recording" at the centre of their analysis. This is unfortunate, because looking at these practices from the perspective of recording-related skills and techniques is likely to result in important insights into the novel ways in which current generations of music enthusiasts tinker with, and learn from, recorded sound.

\section{Entering the mashup community}

As part of a larger research project on online musical appropriation practices (Michielse 2015), I conducted a virtual ethnographic study (Hine 2000) of mashup community Mashstix.com. Most of my fieldwork took place between June 2013 and November 2014, although some of the interactions with my interviewees continued in 2015. Mashstix is not the only online platform where mashup enthusiasts meet up. Other websites, like Acapellas4u (www.acapellas4u.co.uk) and Mashuptown (www.mashuptown.com), are also available. For the purpose of this research, however, I focused primarily on Mashstix because this platform has a more lively discussion forum in comparison to the other communities. On Mashstix, the majority of uploaded tracks get analysed and critiqued by dozens of other community members. For this reason, the platform is a good place to learn more about what mashup enthusiasts themselves find important topics of discussion and about what they consider to be central aspects of their practice.

During my fieldwork, I followed discussions, listened to uploaded works, read reviews and engaged in email correspondences with community members on a daily basis. I also conducted semi-structured qualitative Skype interviews with seventeen members of the community. These interviews lasted between forty-five and ninety minutes (in some instances divided over two separate sessions). The 
members who participated in these interviews were all male, aged between eighteen and forty-five, and located in the following countries: Australia, Belgium, France, Germany, Israel, the UK and the USA. ${ }^{4}$ By extending my online observations with Skype interviews, I was able to get a better idea of the musical and technical interests of these mashup enthusiasts. Moreover, it gave me an opportunity to investigate those aspects of mashup practices which are normally not directly visible on the forums itself, such as the ways in which participants gather and select their source materials or the ways in which they mix and master their work.

All interviewees gave me explicit permission to use their quotes and examples. In order to protect their identities, however, I have decided to use pseudonyms rather than actual usernames in this publication. As noted in the introduction, mashup practices are often seen as deliberate illegal activities. For this reason, mashups enthusiasts are regularly targeted by music industry officials, (new) media platforms and copyright holders. The exact legal status of mashups has always been contested (Roseman 2007), and part of the purpose of this article is to show that there is more to mashup practices than legal issues alone. Yet because of the large number of cease-and-desist letters sent to mashup enthusiasts, the use of pseudonyms is still in the participants' best interest. At the same time, attention for other, more skills-oriented, aspects of mashup practices, is potentially relevant to current legal debates, as it helps us to understand the broader values and meanings produced within these communities.

In this respect, John Shiga, in his article "Copy-and-Persist: The Logic of Mashup Culture" (Shiga 2007), pays special attention to the different skills and challenges that give meaning to mashup practices. As he argues, mashup enthusiasts "develop reputations within the online community by displaying their capacity to discern lyrical and instrumental affinities between disparate songs as well as the capacity and willingness to listen closely to the remixes of others" (Shiga 2007: 95). For Shiga, however, these skills are mainly grounded in listening. If mashup enthusiasts gain esteem in the community, he argues, it is mostly by means of their specialized listening abilities or, as he calls it, forms of "virtuoso listening" (Shiga 2007: 98).

In this article I propose that we should move beyond listening as a core focus. If listening is an important skill in the mashup community, this is true only as part of a wider set of skills in which technical knowhow plays a key role too. ${ }^{5}$ In fact, mashup enthusiasts are often quite humble about their listening capacities. During interviews, participants would regularly dismiss the exceptional status of their hearing abilities, but quickly shift the discussion to other aspects of the practice ("I don't have what musicians call and 'absolute ear'", "I am a technician more than I have really good ears", "You need technical skills ... you need to be able to use [the] software" $).{ }^{6}$ Besides that, for mashup enthusiasts it is not only crucial to be able to understand why recorded tracks sound the way they do; it is also necessary to be able to imagine how these tracks could potentially sound differently, when placed in a new musical context. Such types of creative imagining are always informed by extensive knowledge of both digital audio technology and the available source files. As such, these abilities pertain rather to a "recording consciousness" than to virtuoso listening. 
In the following section I elaborate on the concept of recording consciousness and show how a specific (digital) form of such a consciousness manifests itself in the mashup community. Next, I will focus on two particular aspects of mashup practices in which the role of such a consciousness is especially prominent: the process of analysing and handling source files (what I call "digital crate digging") and the activity of evaluating and critiquing the work of peers (what I call musical "reverse engineering").

\section{The concept of recording consciousness}

Bennett's (1980) conceptualisation of recording consciousness is fruitful precisely because it moves beyond the notion of listening and places the focus more on broader types of musical and technological awareness that have grown central since the rise and spread of recording technologies. The advent of recording technologies brought along an aural culture in which sound and sound source could be radically separated, in both a temporal and a spatial way (Kim 2010; Rösing 1984). Particularly as of the 1960s and 1970s, bands, artists and studio engineers have begun to push the aesthetics of this new aural landscape into new directions, deploying the opportunities of recording technologies and physical media (such as long playing records) in new and innovative ways. For Bennett, this resulted in a situation in which new types of sonic understanding became key, both for consumers of music and for producers of music.

In its broadest sense, then, the concept of recording consciousness refers to the ability to conceptualize (tacitly or explicitly) the "language" of recording (Milner 2009). As such it entails, first of all, an ability to grasp complex and abstract sonic phenomena, including multitrack, stereo fields, fidelity, distortion and sampling. It also refers to a more general understanding of the different ways in which recorded sound manifests itself. Comprehending the characteristics and affordances of different audio media, for example, is tightly linked to the concept of recording consciousness. This is also true for the ability to distinguish between different types of recorded audio such as edits, extended versions, live recordings, demos and remixes. For musicians and engineers in particular, a recording consciousness makes it possible to predict (and imagine) the consequences of studio manipulation in advance as well. As Bennett writes, a recording consciousness allows people "as a purely mental activity, to multi-track, alter dynamics, achieve reverberation and delay effects, equalize according to frequency, and manipulate signal-to-noise rations" (Bennett 1980: 128-129).

In all these examples, the idea of a mental exercise is key. For Bennett, a recording consciousness enables a particular form of aural imagination. What is imagined, however, is not the audio itself, but rather the technologies behind the audio. In other words: a recording consciousness makes it possible to conceptualize how sound is constituted by (or can potentially be constituted by) a particular set of recording technologies and audio formats. For Bennett, the development of such a form of imagination is hardly mysterious. It is an automatic product of a media environment in which recording technologies and recorded music have become ubiquitous. It may also be extended and trained further. In his work, Bennett (1980) describes, for example, how tinkering with the technology 
and trying to copy and mimic particular sounds can be an important way to enhance one's recording consciousness.

At the time when Bennett wrote his theories, however, the media landscape (and the types of musical access it allowed) were completely different. Bennett wrote his theories at a time when recorded music was consumed largely via physical audio media such as records and cassettes. ${ }^{7}$ Nowadays, a wide variety of non-physical files and formats has been added to those media. Particularly in the last two decades, the rise and spread of the networked computer, online music platforms and digital audio formats such as MP3, WAV, and FLAC, have had a strong influence on how music is produced, consumed, and experienced. Moreover, when Bennett developed his theories, multitrack technologies were only accessible in large professional studio settings, while networked digital media were not as ubiquitous yet. Today, anyone with a personal computer or laptop can gain access to near-professional digital audio software programs with the help of which any musical input can be analysed and revised in elaborate aural, visual and mathematical ways (Campbell 2013; Hugill 2008; Väkevä 2010). This has an important impact on how large groups of music enthusiasts use and conceptualize recorded sound. For this reason, it is more appropriate, in my view, to speak of a digital recording consciousness. This involves a form of aural awareness which is developed through an intensive exposure to, and experimentation with, digital audio software programs and interrelated audio files; or, in other words, a type of technical and musical understanding which is attuned to a media environment in which networked technologies and digital audio formats have become key.

While mashup enthusiasts are not the only ones who rely on such a recording consciousness - think, for example, of online remixers who often make use of similar tools and technologies (Michielse 2013; Michielse and Partti 2015) - the mashup community is particularly attuned to it. This has to do with the fact that their practices are less about making variations on songs and more about establishing technical links between existing audio files. Indeed, the role of digital recording consciousness in the mashup community is evident both when we look at the way mashup enthusiasts navigate their source materials and in the way they evaluate tracks from their peers. Both of these processes require an in-depth understanding of the characteristics and affordances of digital audio files and available music software programs.

\section{Navigating digital source files}

Today, the World Wide Web provides us with a form of musical access which is unprecedented in the history of recorded music (Ratliff 2016). For any song that enters the Billboard charts nowadays, hundreds of authorized and non-authorized audio files appear on platforms like YouTube, SoundCloud or Acapellas4u. These include full studio recordings as well as (user-generated) variations, such as a cappella files, instrumentals, multitrack stems, karaoke tracks, cover versions and remixes. The sheer amount of available material provides music enthusiasts with new opportunities, as well as posing new challenges to them (ibid). Indeed, if 
mashup artists enjoy exploring the wide spectrum of potential source materials, they also struggle to navigate an ever expanding network of original and derivative tracks.

In an online context, some of the a cappella files that circulate are so-called "studio" versions, which come from the official multitrack mix, while others are DIY, produced by fellow mashup enthusiasts themselves. This is done by filtering out certain frequencies or by extracting particular parts of the stereo field with help of digital audio workstations (Roseman 2007). The same is true for instrumental tracks that appear online. Some of these are official studio instrumentals, released by the original artist, while others come from cover bands and karaoke sets, or are taken from the multitrack stems of computer games like Rock Band and Guitar Hero. Often these versions differ not only in audio quality, but also in instrumentation and feel. Choosing the right version of a track for a particular mix is thus an important part of the mashup practice. But this is no easy task in an online context in which there is relatively little regulation and audio files are often (purposefully) mislabelled in order to attract attention and retrieve more downloads. On a platform like Acapellas4u, for example, some tracks might be called "official studio recordings" while in reality their audio quality turns out to be less than ideal. Similarly, on YouTube some instrumental tracks that are labelled "official" may in fact be karaoke tracks or user-generated cover versions.

Navigating such a complex landscape of source materials, then, involves extensive processes of, what I call, "digital crate digging". In hip-hop and DJcontexts, the term "crate digging" is traditionally used to refer to the practice of strategically searching for source materials for a new track or mix (Jansen 2011; Katz 2004; McLeod and DiCola 2011; Schloss 2004). The name of the activity comes from the role that (milk) crates play in the search for such source materials. Thrift shops and record stores traditionally stored their (second hand) vinyl records in such crates. For turntablists and DJs, being able to effectively navigate such crates and being able to locate hidden musical gems among the large amounts of recordings was seen as an important way to build prestige within the community.

While scholars like McGranahan (2010) and Sinnreich (2010) question whether crate digging plays a role in the mashup scene, I argue that it does, albeit in a different manner than in the hip-hop and DJ cultures described above. If crate digging is usually intertwined with physical audio media and official studio releases (and thus fits in the context of a more traditional recording consciousness), in the mashup scene it is embedded completely in a new media setting (and thus it pertains more to what I have been calling a digital recording consciousness). In this context, the practice of crate digging becomes closely intertwined with other new media competences such as "new literacies" (Knobel and Lankshear 2007) and "transliteracies" (Hugill 2008; Thomas et al. 2007), in which the ability to navigate (and understand) different online platforms and media applications is key.

Indeed, in their search for the right source materials, mashup enthusiasts need not only need to gain a sense of the musical qualities of the available files (such as genre, tempo and key), but also to understand the recording-technical and new media-related aspects that come with these tracks. They need to ask themselves such questions as: What is the format that the file is in? Where online can it be retrieved? Can it be successfully converted (and/or inserted) in my digital audio 
workstation? Does a particular file include all the instruments and tracks of the original mix, or only a couple? Is it an original instrumental or a (lower quality) karaoke track? Is it a professional release or is it user-generated? Does the file contain traces of unwanted background audio (so-called "spill" or "bleed")? If so, where does it occur, and can it be fixed by available software programs? In some cases, software applications such as Keyfinder and Mixed In Key will be useful because they are able to calculate several basic aspects of the tracks, such as tempo and key. For other, more complicated technical analysis, mashup enthusiasts often rely on their digital audio workstations, which make it possible to analyse the sources in more extensive technical ways.

Often, all of the various meta-data collected through such processes are written down in digital worksheets (in Excel or Word) which list the characteristics of the different available sources. These worksheets can be shared and maintained collectively, but they can also be kept privately. ${ }^{8}$ Mashstix member Chris, for example, told me how he had recently started to make a personal document with all the source files on his hard drive, including all the relevant meta-data of the tracks. Without the help of such a worksheet, he argued, it had become increasingly difficult to make sense of the available tracks and recordings online (Chris 2014). In a similar way, Mashstix member Léon told me how he had spent a lot of time noting down all necessary technical and musical details of his source files (Léon 2014a; 2014b). His worksheet listed aspects such as BPM (beats per minute) and key, but also more personal remarks about the potential usefulness of a file and particular problems he might encounter when trying to work with it in the future.

The ultimate challenge for a mashup artist, then, is to use such knowledge and data to predict how particular tracks will work together musically and technically, and to imagine if (and how) any weaknesses of certain files can be masked in the final mix. As Léon informed me: "I look at [the worksheet] and my imagination is working ... I imagine: 'will it work or will it not [work]?'" (Léon 2014b). Here the role of a digital recording consciousness is key too, as mashup enthusiasts have to base their creative imagination on their acquaintance with the field of online source files and on their understanding of the possibilities and limits of available editing software. While it might seem as if in a digital context any sound can be mixed with any other sound without any effort, this is all but true. Contemporary audio workstations have their limitations too. Digital interventions can easily start to sound odd or unnatural, and thus defeat the final purpose of the mashup, namely: to create a smooth and seamless mix. Depending on the available tools and skills, some technical flaws or issues of a file may well be hidden in the editing process, without it becoming too obvious or distracting, but this can only be achieved through careful reflection. Knowing the tools and being able to judge whether or not there are ways around particular musical or technical obstacles is thus an important skill for mashup enthusiasts.

During the interviews, participants would often talk proudly about those instances in which they managed to push their source materials to their musical and technical limits. Guy, for example, told me how he recently was forced to use a (lower quality) karaoke version of an Aerosmith song, as he was not able to find an official instrumental of that particular track (Guy 2014). In order to mask the 
audio problems with that file, he added short instrumental samples from the original recording, mixing back and forth between the two tracks and, at times, carefully layering the stems over each other. As he explained, the challenge in such a situation is to try and make the source materials sound good, even if many of the files that can be found online are less than perfect. As he said: "You want to do it in such a way that you barely cannot hear it. That people will start to give you the benefit of the doubt and ask 'Is this a real [studio] instrumental or not?'" (Guy 2014). In the same vein, Frank told me how he had managed to work with a particular Michael Jackson a cappella which was considered to be practically useless by the community due to its poor audio quality (Frank 2013). By putting extra effects on the vocals, and by mixing back and forth between the a cappella track and elements from the original studio recording, Frank had managed to mask the audio problems to an extent that his peers started to wonder if he perhaps had gained access to the official studio a cappellas instead.

For those in the community who can work with the software particularly well, producing an entirely new DIY a cappella or instrumental is also a way to showcase a particular aural awareness. Producing a DIY a cappella is a difficult and time-consuming practice which only a minority of the members on Mashstix has fully mastered. It requires an in-depth understanding of how selected frequencies or parts of the stereo field of an audio file can be isolated (a process called "phase cancellation" or "phase inversion"; see also Roseman 2007: 159; Tough 2010: 207). ${ }^{9}$ If done well, however, the DIY-extraction of vocals or backing tracks makes it possible to produce musical combinations that previously were inconceivable. As such it is an important tool when it comes to impressing or surprising the community.

Of course, such efforts only make sense in a context of shared expertise - one in which people will know which source materials are available and will recognize and applaud novel ways of using particular sources and tools. This is why the commenting section on Mashstix is so important: it allows for the collective evaluation and deconstruction of the tracks of peers and provides yet again an opportunity to showcase particular knowledge and skills.

\section{Evaluating the tracks of others}

Like many online music platforms, Mashstix has an extensive forum section for discussing and comparing self-made works with peers. In such discussions, a digital recording consciousness also plays a role, even if somewhat differently than in the case of the crate digging practices discussed above. The forum section provides a context for mashup enthusiasts to deploy their understanding of digital files and the available editing software to give extensive feedback on each other's work. By giving detailed reviews of the works of others, mashup enthusiasts demonstrate their grasp and appreciation of the musical and technical efforts going into those works. Moreover, they show their ability to provide in-depth suggestions for improvement.

A discussion on Mashstix will usually start with a general remark about the "vibe" or the "idea" of a mashup. Participants will give compliments on the choice of artists and songs, or they will say how much they enjoyed the mix as a 
whole. Quickly, however, they will begin to dissect the work and reflect on how particular audio stems were used in the mixing process and how they can potentially be tweaked further. Comments will address, for example, the volume, pitch or the placing of a specific a cappella track in the mix ("Pink's choruses could be turned down a bit", "Bump that vocal up a decibel or two", "Pitch Katy [Perry] up one semitone"). ${ }^{10}$ Comments may also pertain to the timing of particular audio tracks in relation to the rest of the mix ("If you place the voice earlier you'll get a better mix"; "Compare your mashups acapella timing to [the] original"). The role of a digital recording consciousness in these practices becomes especially notable when not only the placing of the stems gets discussed, but also the nature of the digital source files ("Sadly that's a karaoke instrumental", "[That] acapella sounds downright DIY", "The instrumental doesn't have that perfect sound I prefer").

While conducting my fieldwork I came across plenty of examples where more experienced members of the community instantly exposed the use of inferior audio tracks, karaoke instrumentals and (almost exact-sounding) cover-vocal tracks in the works of their peers. Moreover, some could pinpoint exactly which particular version of a source file was used, where it came from, and whether or not there was a better version available online. Such comments too would be immediately followed by suggestions for improvement of the existing mix, usually with detailed reference to the software tools that could be used to optimize the end result.

During such sessions, mashup enthusiasts can be said to engage in a form of musical reverse-engineering. Within an academic context, the term "reverse engineering" is often used to refer to processes of deconstructing and reconstructing certain artefacts (Friesinger and Herwig 2014). The goal of such processes is usually to learn more about how a particular object functions, to see whether it can be improved, and to test and extend one's technical knowledge in the process. In some cases, reverse engineering involves a purely mental process, based solely on speculation about how a particular artefact or technology works. In other cases, however, it may also involve some type of direct (hands-on) interaction with a certain artefact or technology, whereby the artefact is literally reworked.

On Mashstix both forms of reverse engineering occur. While participants will often evaluate and critique a mashup solely based on their general experience with the software and source files, it is not uncommon for them also to try to recreate certain elements of a mix within their own audio workstations. For example, when discussions about the BPM (beats per minute) or the key of particular tracks become particularly heated, participants will sometimes look up the source files themselves, re-calculate their properties, or see (and experience) how they behave in the context of a digital audio workstation. Because many of the source files are accessible to anyone with an internet connection, it is relatively easy to test certain scenarios and see if there are any alternative solutions to particular musical or technical problems.

Trying to recreate the work of a peer can also be a very educational practice for the participants involved. Especially for new members in the community it can be quite fruitful to try to mimic and recreate an already existing mashup. Such 
activity may reveal a lot about the kind of tricks and techniques for achieving a perfectly blended mix. During my fieldwork I also encountered so-called "mirror versions" of mashups. These are uploads in which one mashup enthusiast uses the same musical combination earlier created by another community member, but then with the acapella and instrumental switched around. If, for example, one community member would mix the vocals from a Metallica track with the instrumental version of a Britney Spears song, another member would use the instrumental of that Metallica track and try to fit it with the vocals of that Britney Spears song. While such experiments will not always be aesthetically pleasing, they are still regarded as valuable in the community because they reveal something about the manner in which certain files do (or do not) fit together. As such it provides an opportunity for collective discussion and debate.

Taking into account such examples, it becomes clear that these processes are not strictly about showcasing a digital recording consciousness to the rest of the community, but also about collectively developing and extending such form of aural awareness further. By participating in these practices and by communally evaluating and improving uploaded works, mashup enthusiasts are able to slowly increase their feel for the online source materials and audio editing software. Indeed, as members like Chris and John revealed to me, the main goal is always to learn and further develop musical and technical understanding. As Chris said: "You come here to get feedback and to learn and to develop" (Chris 2014). Or in the words of John: "You get ideas from other people, you get ideas from their failures. You may hear a mashup that doesn't work and you go 'oh, you know what would work?', and then you go back and work on that ... From the forums you learn" (John 2013). This ongoing quest for better skills and knowledge is unmistakably the driving force behind these practices.

\section{Conclusions}

As I have shown, mashup communities like Mashstix are geared to a very particular form of aural awareness in which a wide set of digital audio files and interrelated software programs are key. Calling this awareness a "digital recording consciousness", I argued that it plays a crucial role in the ways in which mashup enthusiasts locate and analyse potential source materials (so-called "digital crate digging"). It also plays an important part in the way they discuss and critique each other's work (so-called musical "reverse engineering"). Throughout the article, I have illustrated how mashup enthusiasts are strongly interested in trying to map the possibilities and limits of recorded songs in a new media landscape. They see it as a challenge to learn as much as possible about available source files, their variations, and the different ways in which they can be manipulated, enhanced and reworked. Moreover, with help of the community, mashup enthusiasts collectively explore the different ways in which they can put practical knowledge about digital source materials and audio editing software to use.

So far, such aspects of mashup practices have received little attention. Much academic literature still frames mashup practices in the context of illegality and subversion. In those cases, where the subversive or political aspects of the practice are not foregrounded, mashups are regularly perceived as rather 
regressive forms of musical production (see, for example, Navas 2010; Reynolds 2011). Such evaluations, however, tend to overlook the community interactions that are a crucial part of the practice and the extensive skills sets that lie at the basis of mashup activities. Although the amount of skills-based research in this area is slowly increasing, more community-based ethnographic research is necessary to further understand and map the different types of skill and know-how embedded and explored in these communities.

Producing a mashup involves a complex set of tasks accompanied by an array of different technical and creative struggles. It is precisely through these struggles that mashup enthusiasts find meaning in their practice, because it helps them to advance their musical and technological understandings and sensibilities. That today it is still necessary to break the law in order to experiment with, and learn from, recorded music in such ways is rather a burden for mashups enthusiasts than a defining feature of their practice.

\section{Endnotes}

${ }^{1}$ Parts of the arguments and examples of this article are based on a chapter of my PhD dissertation (Michielse 2015).

${ }^{2}$ One of the biggest compliments that mashup enthusiasts can give each other is stating that a particular mashup "sounds like an original". Such a comment signifies that the blending of the source files was so successful (musically and technically) that it seems as if the two sources have always meant to be together.

${ }^{3}$ The goal of this article is to show how mashup enthusiasts themselves think and talk about their practices. As my ethnographic fieldwork shows, for many of them illegality and subversion are not key aspects of their practices. While they might encounter legal problems during their online activities, they rarely see it as key components of their creative and musical identities. This does not mean however that other parties (such as music industry officials, professional music artist or legal representatives) think about these matters in the same way. From their perspective, legal and ethical issues might well be considered key concerns when it comes to online mashup practices. Authors such as Cloonan and Garofalo (2003) and Burkart and McCourt (2006) discuss such perspectives more extensively.

4 Like in other remix and mashup communities, the overrepresentation of male participants is very prominent on Mashstix. The reasons for this gender bias are diverse and complex, as other research on the topic has revealed (see, for example, Gavanas and Reitsamer 2013; Goodwin 2004).

${ }^{5}$ While this is partly acknowledged by Shiga (2007) when he writes about the role of digital audio workstations and software programs like Mixed in Key, it is not the main focus of his article. Also, he does not discuss the topic of aural imagination, something which is very much central in the theory of recording consciousness and thus also in this article.

${ }^{6}$ The quotes presented here are drawn from several personal interviews as conducted between June 2013 and November 2014.

${ }^{7}$ From 1982 onwards, these audio media were also joined by the compact disc. While the compact disc had an important role in bringing digital audio technologies to wider 
music audiences, it does not yet represent the kind of (networked) digital culture that is investigated in this article. The same is true for early digital tools that were introduced in the professional recording studios around that same time period (the end of the 1970s and beginning of the 1980s), which may have involved earlier forms of the aural awareness that I discuss here. When I use the term 'digital recording consciousness' in this article, however, it is primarily meant to signify forms of aural awareness that have developed since the rise of the networked computer and interrelated software programs and audio technologies.

${ }^{8}$ Website Acapellas4u has, for example, recently experimented with a public worksheet in which some of the more popular a cappella files are listed, including their musical and technical characteristics. This worksheet was distributed to all of the registered members of the platform.

${ }^{9}$ When they are released online, self-made (DIY) a cappellas and instrumentals often carry the name of the mashup enthusiasts who produced them. For example: "Idina Menzel - Let it Go (mashnographer diy a cappella)". This is another way in which the production of DIY a cappellas can be used to gain prestige in the community.

${ }^{10}$ The comments presented here are drawn from participant discussion on various parts of the Mashstix forums, taking place between June 2013 and November 2014.

\section{References}

\section{Bibliography}

Babich, B. 2014. Adorno's Radio Phenomenology: Technical Reproduction, Physiognomy and Music. Philosophy and Social Criticism 40(10): 967-996.

Bennett, H.S. 1980. On Becoming a Rock Musician. Amherst, MA: University of Massachusetts Press.

Brøvig-Hanssen, R. and Harkins, P. 2012. Contextual Incongruity and Musical Congruity: The Aesthetics of Humour of Mash-Ups. Popular Music 31(1): 87104.

Burkart, P. and McCourt T. 2006. Digital Music Wars. Ownership and Control of the Celestial Jukebox. Oxford: Rowman and Littlefield.

Campbell, M. 2013. Out of the Basement. Youth Cultural Production in Practice and in Policy. Montreal: McGill-Queen's University Press.

Cloonan, M. and Garofalo, R. Eds. 2003. Policing Pop. Philadelphia, PA: Temple University Press.

Demers, J. 2006. Steal This Music. How Intellectual Property Law Affects Musical Creativity. Athens, GA: The University of Georgia Press.

Friesinger, G. and Herwig, J. Eds. 2014. The Art of Reverse Engineering. OpenDissect-Rebuild. Bielefeld: Transcript.

Gavanas, A. and Reitsamer, R. 2013. DJ Technologies, Social Networks and Gendered Trajectories in European DJ Cultures. In B.A. Attias, A. Gavanas, and H.C. Rietveld Eds. DI Culture in the Mix. Power, Technology, and Social Change in Electronic Dance Music. New York: Bloomsbury: 51-77.

Goodwin, A. 2004. Rationalization and Democratization in the New Technologies of Popular Music. In S. Frith Ed. Popular Music. Critical Concepts 
in Media and Cultural Studies. Vol. 2: The Rock Era. London: Routledge: 147169.

Hine, C. 2000. Virtual Ethnography. London: Sage.

Hugill, A. 2008. The Digital Musician. New York: Routledge.

Howard-Spink, S. 2005. Grey Tuesday, Online Cultural Activism and the Mash-

Up of Music and Politics. First Monday 9(10): n.p.

Jansen, B. 2011. Where Credit is Due. Cultural Practices of Recorded Music.

Amsterdam: Amsterdam University. PhD Thesis.

Katz, M. 2004. Capturing Sound. How Technology Has Changed Music. Berkeley, CA: University of California Press.

Kealy, E.R. 1990. From Craft to Art. The Case of Sound Mixers and Popular Music. In S. Frith and A. Goodwin Eds. On Record. Rock, Pop, and the Written Word. London and New York: Routledge: 207-220. First edition 1979.

Kim, S.J. 2010. Imaginal Listening: A Quaternary Framework for Listening to Electroacoustic Music and Phenomena of Sound-Images. Organised Sound 15(1): 43-53.

Knobel, M. and Lankshear, C. 2007. A New Literacies Sampler. New York: Peter Lang.

Lave, J. and Wenger, E. 1991. Situated Learning. Legitimate Peripheral Participation. Cambridge: Cambridge University Press.

McGranahan, L. 2010. Mashnography: Creativity, Consumption and Copyright in the Mashup Community. Providence, RI: Brown University. PhD Thesis.

McLeod, K. 2005. Confessions of an Intellectual (Property): Danger Mouse, Mickey Mouse, Sonny Bono, and My Long and Winding Path as a Copyright Activist-Academic. Popular Music and Society 28(1): 79-93.

McLeod, K. and DiCola, P. 2011. Creative License. The Law and Culture of Digital Sampling. Durham, NC: Duke University Press.

Michielse, M. 2013. Musical Chameleons: Fluency and Flexibility in Online Remix Contests. M/C Journal 16(4): n.p.

Michielse, M. 2015. Remix, Cover, Mash. Remediating Phonographic-Oral Practice Online. Maastricht: Maastricht University. PhD Thesis.

Michielse, M. and Partti, H. 2015. Producing a Meaningful Difference: The Significance of Small Creative Acts in Composing within Online Participatory Remix Practices. International Journal of Community Music 8(1): 27-40.

Middleton, R. 1990. Studying Popular Music. Milton Keynes: Open University Press.

Milner, G. 2009. Perfecting Sound Forever. The Story of Recorded Music. London: Granta.

Navas, E. 2010. Regressive and Reflexive Mashups in Sampling Culture. In S. Sonvilla-Weiss Ed. Mashup Culture. New York: Springer: 157-177.

Ratliff, B. 2016. Every Song Ever. Twenty Ways to Listen to Music Now. London: Allen Lane.

Reynolds, S. 2011. Retromania. Pop Culture's Addiction to its Own Past. London: Faber and Faber.

Roseman, J. 2007. Audio Mashup Construction Kit. Indianapolis, IN: Wiley Publishing. 
Rösing, H. 1984. Listening Behaviour and Musical Preference in the Age of "Transmitted Music". Popular Music 4: 119-149.

Schloss, J.G. 2004. Making Beats. The Art of Sample Based Hip-Hop. Middletown, CT: Wesleyan University Press.

Shiga, J. 2007. Copy-and-Persist: The Logic of Mash-Up Culture. Critical Studies in Media Communication 24(2): 93-114.

Sinnreich, A. 2010. Mashed Up. Music, Technology, and the Rise of Configurable Culture. Amherst, MA: University of Massachusetts Press.

Tapscott, D. and Williams, A.D. 2006. Wikinomics. How Mass Collaboration Changes Everything. London: Portfolio.

Thomas, S., Josephs, C., Laccetti, J., Mason, B., Mills, S., Perril, S. and Pullinger, K. 2007. Transliteracy: Crossing Divides. First Monday. 12(12): n.p.

Tough, D. 2010. The Mashup Mindset: Will Pop Eat Itself? In G. Plasketes Ed. Play it Again: Cover Songs in Popular Music. Aldershot: Ashgate: 205-212.

Väkevä, L. 2010. Garage Band or GarageBand®? Remixing Musical Futures. British Journal of Music Education 27(1): 59-70.

Wenger, E. 1998. Communities of Practice. Learning, Meaning, and Identity. Cambridge: Cambridge University Press.

\section{Interviews}

Chris. 2014. Skype Interview by Maarten Michielse. 24 May. Frank. 2013. Skype Interview by Maarten Michielse. 7 October.

Guy. 2014. Skype Interview by Maarten Michielse. 4 September. John. 2013. Skype Interview by Maarten Michielse. 21 November. Léon 2014a. Skype Interview by Maarten Michielse. 3 February. 2014b. Skype Interview by Maarten Michielse. 20 May. 